\title{
Ultra-optical characterization of thin film solar cells materials using core/shell absorber layer
}

\author{
Ahmed Thabet ${ }^{1,2}$, Safaa Abdelhady ${ }^{1}$, Youssef Mobarak ${ }^{1,3}$ \\ ${ }^{1}$ Nanotechnology Research Center, Electrical Engineering Department, Faculty of Energy Engineering, Aswan University, \\ Aswan, Egypt \\ ${ }^{2}$ Electrical Engineering Department, College of Engineering and Information Technology, Buraydah Colleges, Buraydah, Saudi Arabia \\ ${ }^{3}$ Electrical Engineering Department, Faculty of Engineering, King Abdulaziz University, Jeddah, Saudi Arabia
}

\begin{tabular}{l} 
Article Info \\
\hline Article history: \\
Received May 31, 2021 \\
Revised Aug 4, 2021 \\
Accepted Sep 1, 202 \\
\hline Keywords: \\
Core/shell \\
Energy conversion \\
Heterojunction \\
Quantum dot \\
Quantum efficiency \\
Solar cell
\end{tabular}

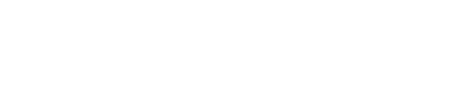

Corresponding Author:

Safaa Abdelhady

Department of Electrical Engineering, Aswan University

Sahary Road, Aswan 81511, Egypt

Email: engsafaa33@gmail.com

\begin{abstract}
This paper investigates on new design of heterojunction quantum dot (HJQD) photovoltaics solar cells $\mathrm{CdS} / \mathrm{PbS}$ that is based on quantum dot metallics $\mathrm{PbS}$ core/shell absorber layer and quantum dot window layer. It has been enhanced the performance of traditional HJQD thin film solar cells model based on quantum dot absorber layer and bulk window layer. The new design has been used sub-micro absorber layer thickness to achieve high efficiency with material reduction, low cost, and time. Metallicssemiconductor core/shell absorber layer has been succeeded for improving the optical characteristics such energy band gap and the absorption of absorber layer materials, also enhancing the performance of HJQD ITO/CdS/QDPbS/Au, sub micro thin film solar cells. Finally, it has been formulating the quantum dot (QD) metallic cores concentration effect on the absorption, energy band gap and electron-hole generation rate in absorber layers, external quantum efficiency, energy conversion efficiency, fill factor of the innovative design of HJQD cells.
\end{abstract}

This is an open access article under the CC BY-SA license.

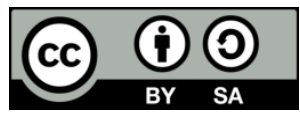

\section{INTRODUCTION}

Researchers are making considerable efforts to develop solar cells based on alternative materials because silicon is an indirect band gap material with a low absorption coefficient. Due to the low absorption, polycrystalline silicon solar cell structures must have a thickness in the range of $200 \mathrm{~m}$, which makes the overall cost higher. We have earlier reported several non-silicon intermediate band gap materials that can be used for solar cell applications [1]-[4]. To overcome such limitations, thin-film solar cells, aiming at reducing cost by decreasing material consumption, will play an important role in future photovoltaic market. Unfortunately, a primarily unavoidable drawback of a thin-film solar cell is its poor optical absorption, which is caused by the thinner active layer and limits the power conversion efficiency with increasing temperature of this type of solar cells. To increase the optical absorption, different light trapping technologies have been extensively used to enhance the light absorption ability of thin-film solar cells [4]-[9]. The quantum dots (QDs) have been reported as promising third generation solar cells; quantum dots can be used in all Solar cells to decrease cost, increase absorption and efficiency by controlling the size of the quantum dots, since several properties can change due to any decrease in the size of nanoparticles [10], [11]. QDs have been incorporated different types of Solar cells such as: schottky solar cells, depleted heterojunction solar cells (SCs), hybrid organic/inorganic solar cells and quantum dot sensitized SCs [12]-[16]. The $3^{\text {rd }}$ generation 
technology nanostructured light trapping is a promising way to improve the efficiency in thin-film solar cells recently but it still under research due to their low efficiency [12]-[16]. Metal-semiconductor core/shell nanostructures have attracted a lot of attention due to their potential applications in optoelectronic devices. The metallic core enhances charge separation and improves absorption of light in the semiconductor during photo stimulation, so increasing the light harvesting efficiency of the semiconductor. When the differences in work function of the metal and semiconductor components and tune core/shell nanostructures during synthesis were tailored such as shell thickness and configuration of core and shell, the improved performance may be recognized. In addition, the interfacial structure may affect on the electronic properties of core-shell nanoparticles [17], [18]. The charge transfer in metal-semiconductor nanocomposites mechanism is used to approve a large improvement about 40 times of $\mathrm{Au} \mathrm{CdS}$ core-shell, Also, the surface plasmon wave on gold surface can be used to excite electrons of Au to an excited state and transfer to the conduction band of CdS and recombine with holes in the valence band. So, it leads to the improved band gap and defect emissions in CdS nanostructures [19]. In this paper, the proposal model has been used the merits of QD metallicsemiconductor core/shell structure to enhance the performance of traditional CdS/QDPbS HJ-QDSc model. It has been used metallic- semiconductor core/shell absorber layer with quantum dot window layer to get high efficiency with lesser usage material based on sub micrometer thickness absorber layers [20]-[23].

\section{DESIGN MODEL}

Metal-semiconductor hetero-nanostructures exhibit different properties than the individual ingredients due to the intense interaction between metal and semiconductor. Surface plasmon resonances (SPR) in metal can be modulated by the semiconductor ingredient in hetero-structures. Through near-field interactions, energy could flow from the excited state of semiconductor to the plasmon, on the other side, plasmon-exciton interaction can also bring a modification of the radiative and nonradiative properties for semiconductor, changing the emission behaviors of semiconductor (enhancement or quenching). With appropriate band structures, charge transfer process like photo-excited electrons in semiconductor transferring to metal could suppress the direct recombination of carriers and promote efficient charge separation, resulting in a significant enhancement in the photoelectric conversion efficiency in solar cell [24]-[26]. The core-shell quantum dot dielectric function has been obtained using the maxwell garnett (MG) expression for spherical inclusions in explicit form [27].

$$
\varepsilon_{\text {efic }-\mathrm{s}}=\varepsilon_{\text {shell }} \frac{\left(\varepsilon_{\text {core } 1}+2 \varepsilon_{\text {shell }}\right)+2 f_{\text {core } 1}\left(\varepsilon_{\text {core } 1}-\varepsilon_{\text {shell }}\right)}{\left(\varepsilon_{\text {core } 1}+2 \varepsilon_{\text {shell }}\right)-f_{\text {core } 1}\left(\varepsilon_{\text {core } 1}-\varepsilon_{\text {shell }}\right)}
$$

Where $f_{\text {core } 1}$ the core filling factor:

$$
f_{\text {core } 1}=\left(\frac{R_{1}}{R_{2}}\right)^{3}
$$

$R_{1}$ radius of the quantum dot metallic core material. $R_{2}$ radius of the quantum dot semiconductor shell material. $\varepsilon_{\text {shell }}$ is dielectric constant of quantum dot shell semiconductor layer material that described by drude model as shown in [28]-[31] as in (3):

$$
\varepsilon_{\text {shell }}=\varepsilon_{\text {shell } \infty}\left(1-\frac{\omega_{b}^{2}}{\omega^{2}+i \omega\left(\gamma_{a Q D}\right)}\right)
$$

where $\omega_{b}$ is the plasma angular frequency of semiconductor layer material and $\mathrm{y}_{\mathrm{aQD}}$ is the macroscopic damping constant.

To reflect the finite size of the nanoparticles, a term that depends on the size of the particle added to the damping constant as shown in (4).

$$
y_{a Q D}=\gamma_{m b}+\left(\frac{3 v_{f b}}{4 R}\right)
$$

$v_{f b}$ is the fermi velocity of semiconductor layer material. $\varepsilon_{\text {shell } \infty Q D}$ is the infinity dielectric constant of QD semiconductor shell layer material which calculated as in (5). 


$$
\varepsilon_{\text {shell } \infty Q D}=\varepsilon_{o}\left(1+\frac{\omega_{b}^{2}}{\left(E_{g(\text { Qdots })}\right)^{2}}\right)
$$

$\varepsilon_{\text {shell } \infty Q D}$ is the infinity dielectric constant of QD shell layer material which is lesser than the value of bulk material due to a lot of reasons; first, its nano-confined dimension that is lower than the incident wavelength so the refractive index reduces. Second reason, the refractive index of a semiconductor decreases with the increase in the energy band gap according to various empirical rules.

As shown in (5) the increase in the energy band gap of quantum dot material than the value of bulk material decreases the infinity dielectric constant. The refractive index in quantum dot thin films reduced so it is a great advantage in solar cells application where the reflection also decreased so absorption increases [31]-[34]. The energy band gap $E_{g(\text { Qdots })}$ of quantum dot layer material can be approximated by [30]-[32].

$$
E_{g(\text { Qdots })}=E_{\text {gbulk }}+\frac{\pi^{2} h^{2}}{2 R^{2}}\left(\frac{1}{m_{e b}}+\frac{1}{m_{h b}}\right)-\frac{1 \cdot 8 Q^{2}}{4 \pi \varepsilon_{b} \varepsilon_{o} R_{2}}
$$

Where

$R_{2} \quad$ : radius of QD layer material

$m_{e b}:$ the electron effective mass for layer material

$m_{h b} \quad$ : the hole effective mass for layer material

$h \quad:$ plank constant

$\varepsilon_{o} \quad:$ the permittivity of free space

Q : elementary charge

Varshni relation describe the temperature dependence of the bandgap in semiconductors which using in absorber or window layer as in [33]. $\varepsilon_{\text {core } 1}$ is dielectric constant of core metallic material that can be described by the drude model [35] as in (7):

$$
\varepsilon_{\text {core } 1}=\varepsilon_{\text {INTRi }}+1-\frac{\omega_{p i}^{2}}{\omega^{2}+i \omega\left(\gamma_{m i}+\left(\frac{3 v_{f i}}{4 R_{1}}\right)\right)}
$$

where, $\gamma_{m i}$ is the macroscopic damping constant of core metallic material. $\omega_{p i}, v_{f i}$ are plasma angular frequency and fermi velocity of core metallic material.

The electron-hole generation rate in the core/shell absorber layer using individual metallic nanoparticles can be written based on [34], [35] as (8):

$$
G_{i c s}(\lambda)=\frac{\alpha_{b i c s}(\lambda) e^{-\alpha_{w i Q D}\left(d_{w}\right)}[1-R(\lambda)] \lambda I_{o}(\lambda)}{h c}
$$

where, $\lambda$ is wavelength, $I_{o}(\lambda)$ is the intensity of the solar spectral, $c$ is the speed of light, $h$ is Plank constant, $\alpha_{\text {bics }}(\lambda)$ is the absorption of the core-shell absorber layer. $\alpha_{w i Q D}$ is the absorption of quantum dot window layer in core-shell thin film solar cells. $\alpha_{b i c s}(\lambda)$ and $\alpha_{\text {wiQD }}$ can be calculated by the Beer-Lambert's law based on refractive index of layers as [31], [35].

Whatever, $J_{\text {diodics }}(V)$ is the forward diode current for heterojunction quantum dot thin film solar cell based on core/shell absorber layer and quantum dot window layer based on [33]-[35] as in (9):

$$
J_{\text {diodics }}(V)=J_{\text {oics }}\left(\exp \left(\frac{Q\left(V+J(V) R_{\text {ser }}\right)}{n K T}\right)-1\right)
$$

$J_{\text {Oics }}$ is reverse saturation current density in new design for heterojunction quantum dot thin film solar cells based on metallic-semiconductor core/shell absorber layer calculated based on ref. [31], [35]. Where, V is applied voltage. Joics is reverse saturation current density in HJQD cells using metallic-semiconductor core/shell absorber layer. $\mathrm{R}_{\text {ser }}$ is the series resistance. $\mathrm{n}$ is diode ideality factor. $\mathrm{T}$ is absolute temperature.

$E_{\text {gbics }}$ is the energy band gap of core/shell absorber layer material that is affected by the metallic nanoparticles. The energy band gap of a semiconductor enhances with decreasing refractive index according to various empirical rules and expressions of refractive index and energy band gap. The energy band gap of metallic-semiconductor core/shell absorber layer material $E_{g b i}$ calculated as shown [35], [36]: 


$$
E_{\text {gbics }}=\frac{36.3}{e^{n_{f i c-s}}}
$$

The total photo generated current density $J_{\text {phics }}(V)$ using quantum dot metallic-semiconductor core/shell absorber layer and quantum dot window layer which obtained by integrating over all incident photon wavelengths of the solar spectrum [31], [34], [35].

$$
J_{\text {phics }}(V)=\int_{0}^{\infty} J_{\text {Tics }}(\lambda . V) d \lambda
$$

Where, the resultant photocurrent density $J_{\text {Tics }}(\lambda . V)$ and the net external current density $J_{\text {indcs }}(V)$ from a solar cell that is quantum dot metallic-semiconductor core/shell absorber layer and quantum dot window layer and the open circuit voltage equation is expressed as in [31], [34], [35].

$$
J_{\text {indcs }}(V)=J_{\text {phics }}(V)-J_{\text {dics }}(V)-\left(\frac{V+J(V) R_{\text {ser }}}{R_{\text {sh }}}\right)
$$

Where, $R_{s h}$ is the shunt resistance:

$$
V_{\text {ocics }}=\left(\frac{K T}{Q}\right) \ln \left[\frac{J_{\text {phics }}}{J_{O}}+1\right]
$$

The output power density of the new heterojunction quantum dot solar cell based on metallic-semiconductor core/shell absorber layer structure and QD window layer.

$$
P_{i c s}=J_{\text {phics }} \times V
$$

$P_{\text {maxics }}$ is the maximum power point density of the proposals cells which estimated from $P_{i c s}-\mathrm{V}$ curve

On the other hand, the calculation of fill factor to an excellent accuracy and the final equation for the efficiency of the new heterojunction quantum dot solar cell based on metallic-semiconductor core/shell absorber layer structure and quantum dot window layer as in [35] as in (17):

$$
\begin{aligned}
& F . F_{\text {icore-shell }}=\frac{P_{\text {maxics }}}{V_{\text {ocics }} \times J_{\text {phics }}} \\
& \eta_{\text {icore-shell }}=\frac{J_{\text {phics }} V_{\text {ocics }} F . F_{\text {icore-shell }}}{P_{\text {in }}} \times 100
\end{aligned}
$$

Whatever, the external quantum efficiency $E Q E_{\text {icore-shell }}(\lambda)$ of the new heterojunction quantum dot solar cell based on metallic-semiconductor core/shell absorber layer and quantum dot window layer structure has been calculated by (18) [35]:

$$
E Q E_{\text {icore-shell }}(\lambda)=\frac{J_{\text {phics }}(\lambda)}{Q \emptyset(\lambda)}
$$

where, $\emptyset(\lambda)$ is the spectral photon density.

\section{SELECTED MATERIALS AND PARAMETERS OF MODELS}

The aim of this paper is improving the efficiency and performance of traditional models that are based on sub micro absorber layer thickness for achieving high efficiency with less absorber layer thickness for reductional cost of materials by using metallic-semiconductor core/shell absorber layer of selected HJQD models. Thus, the core/shell absorber layer thin film solar cells materials parameters are achieved high efficiency and J-V characteristics of ITO/CdS/PbS/Al with respect to traditional HJQD models [21], [31].

Table 1 and Table 2 show the main parameters of usage materials and parameters of HJQD thin film models based on QD window layer and metallic-semiconductor core/shell absorber layer; the results have been obtained using QD window layer radius $1 \mathrm{~nm}$ and QD core/shell with QD shell layer material radius $3 \mathrm{~nm}$ and under AM1.5 solar irradiation. 
Table 1. Parameters of proposal HJQD cells models based on core/shell absorber layer and QD window layer [21], [31]

\begin{tabular}{cc}
\hline Parameters & $\mathrm{CdS} / \mathrm{PbS}$ \\
\hline Absorber layer thickness $(\mathrm{nm})$ & 500 \\
Window layer thickness $(\mathrm{nm})$ & 100 \\
Front layer thickness $(\mathrm{nm})$ & 100 \\
Electron lifetime (s) & $10^{-9}$ \\
$\quad$ Hole lifetime (s) & $10^{-9}$ \\
$N_{a}-N_{d}$ the concentration of uncompensated & $0.19 \times 10^{10}$ \\
$\quad$ acceptors $\left(\mathrm{cm}^{-3}\right)$ & 1.4 \\
Diode quality factor & 2.1 \\
Series resistance $\left(\Omega . \mathrm{Cm}^{2}\right)$ & 204 \\
Shunt resistance $\left(\Omega . \mathrm{Cm}^{2}\right)$ & \\
\hline
\end{tabular}

Table 2. Characteristics of usage materials as substrate layer or QD core materials in QD shell absorber layer for HJQD thin film models [35]

\begin{tabular}{cccc}
\hline Materials & $\begin{array}{c}\text { Plasma angular frequency } \\
\left(\omega_{p} 10^{16} \mathrm{rad} / \mathrm{s}\right)\end{array}$ & $\begin{array}{c}\text { Damping constant } \\
\left(\gamma_{m} 10^{13} \mathrm{~s}^{-1}\right)\end{array}$ & $\begin{array}{c}\text { Fermi velocity } \\
\left(v_{f} 10^{6} \mathrm{~m} / \mathrm{s}\right)\end{array}$ \\
\hline Cesium $(\mathrm{Cs})$ & 0.54 & 0.756 & 0.75 \\
Lithium $(\mathrm{Li})$ & 1.225 & 1.85 & 1.29 \\
Cupper $(\mathrm{Cu})$ & 1.03 & 5.26 & 1.57 \\
Silver $(\mathrm{Ag})$ & 1.40 & 2.80 & 1.39 \\
Aluminum $(\mathrm{Al})$ & 1.09 & 12.4 & 2.03 \\
Molybdenum $(\mathrm{Mo})$ & 0.19 & 1.13 & - \\
\hline
\end{tabular}

\section{RESULTS AND DISCUSSION}

The behavior and characterization of the innovative design of heterojunction quantum dot of photovoltaic solar cell which based on QD window layer and QD core-shell absorber layer has been layout as follows: Figure 1 shows the metallic cores concentration effect on the optical characteristics of metallic-PbS core/shell absorber layers for new HJQD (QDCdS/QDPbS). Figure 1 shows that using metallic-PbS core/shell structure enhanced the optical characteristics of QDPbS with increasing the concentration of metallic cores $(\mathrm{Ag}, \mathrm{Cu}, \mathrm{Li}$ or $\mathrm{Al})$ inside $\mathrm{QDPbS}$ shell by decreasing dielectric constant, refractive index, increasing energy band gap so the absorption coefficient and electron -hole generation rate in QDPbS layer enhanced. Figure 2 shows the quantum dot metallic cores concentration effect on the generation rate and absorption coefficient in absorber layer of heterojunction quantum dot $\mathrm{CdS} / \mathrm{PbS}$ thin film solar cell. Using Silver, Copper, Aluminum, Cesium or Lithium quantum dot cores in quantum dot $\mathrm{PbS}$ shell layer increased the electron-hole pair generation rate in the $\mathrm{PbS}$ absorber layer. The absorption coefficient of metallics- $\mathrm{PbS}$ core/shell absorber layer increased by increasing the volume fraction. Cesium has been the best quantum dot core for enhancing the absorption coefficient, then; quantum dot Copper core has been the second order for improving the absorption coefficient. Silver has been the least one for improving the absorption coefficient of $\mathrm{PbS}$ shell layer.

On the other hand, Figure 3 describes the joint venture (JV) and photovoltaic (PV) characteristics of heterojunction quantum dot ITO/CdS/PbS/Au thin film solar cells based on quantum dot core-shell absorber layer and quantum dot window layer. The short circuit current density, open circuit voltage and maximum output power density of heterojunction quantum dot $\mathrm{CdS} / \mathrm{PbS}$ thin film solar cells has been increased by using $20 \mathrm{wt} \%$ of Silver, Aluminum, Lithium, Copper or Cesium quantum dot cores in the QD PbS shell layer due to increasing the optical properties of quantum dot $\mathrm{PbS}$ shell layer and declining the reverse saturation current density of the cell. The most enhancements have been occurred by using quantum dot Cesium core in the quantum dot $\mathrm{PbS}$ absorber layer with increasing the wavelength. Copper has been the second order for enhancing the external quantum efficiency of heterojunction quantum dot ITO/CdS/PbS/Al thin film solar cell.

Figure 4 shows the quantum dot metallic cores concentration effect on the energy conversion efficiency and fill factor of heterojunction quantum dot $\mathrm{CdS} / \mathrm{PbS}$ thin film solar cell based on quantum dot window layer and quantum dot metallics-PbS core/shell layer material. Anew solar cell design that using quantum dot metallic cores of Silver, Copper, Lithium, Aluminum or Cesium in PbS quantum dot shell layer could raise the energy conversion efficiency and fill factor of heterojunction quantum dot $\mathrm{CdS} / \mathrm{PbS}$ thin film solar cell with increasing the volume fraction. The external quantum efficiency of heterojunction quantum dot $\mathrm{CdS} / \mathrm{PbS}$ thin film solar cells has been increased by using $20 \mathrm{wt} \%$ of Silver, Aluminum, Lithium, Copper or Cesium quantum dot cores in the QD PbS shell layer due to increasing the optical properties of quantum dot $\mathrm{PbS}$ shell layer and declining the reverse saturation current density of the cell. 

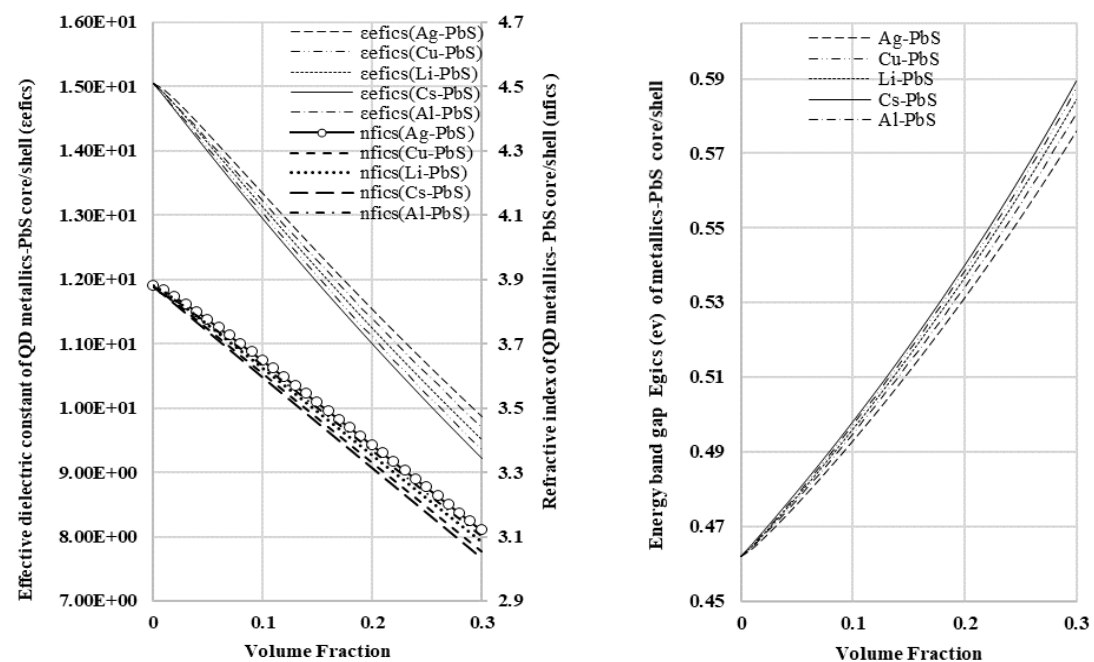

Figure 1. Refractive index, Effective dielectric constant and energy band gap of QD metallics-PbS core/shell

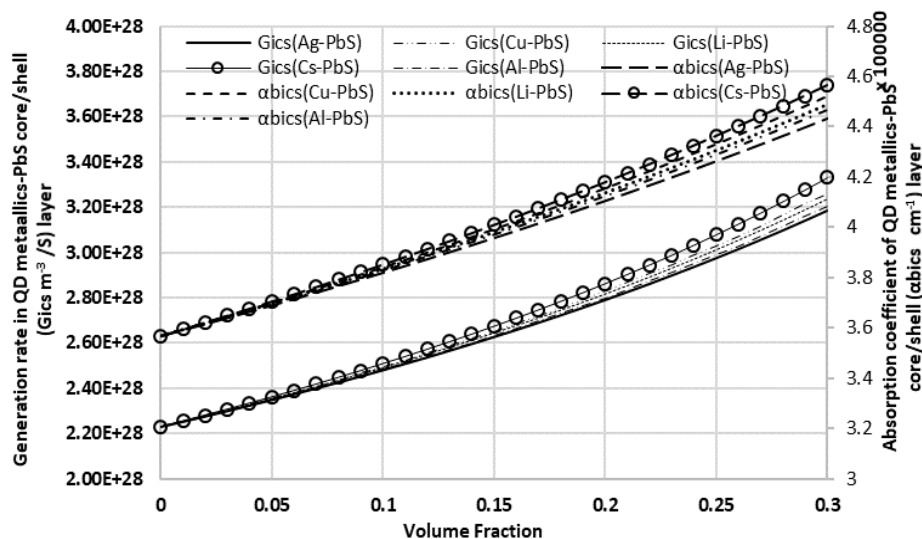

Figure 2. Generation rate, absorption coefficient and reverse saturation current density in $\mathrm{PbS}$ shell layer of heterojunction quantum dot ITO/QDCdS/metallics-PbS/Au thin film solar cell
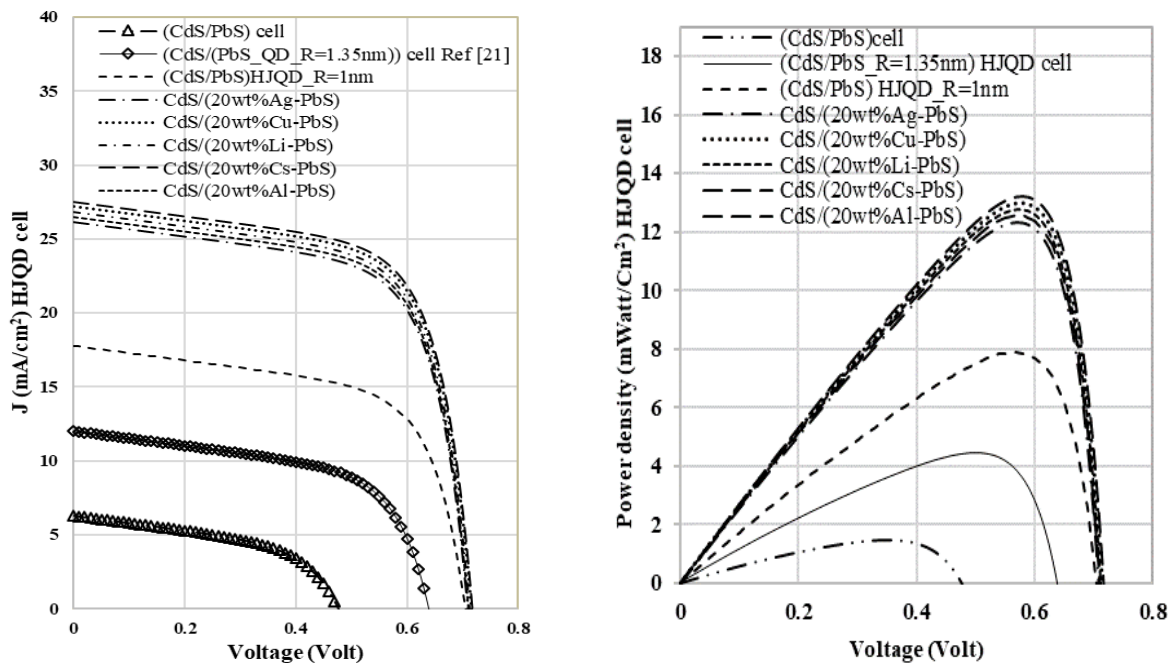

Figure 3. J-V and P-V characteristics of heterojunction quantum dot ITO/QDCdS/metallics-PbS/Au thin film solar cells 

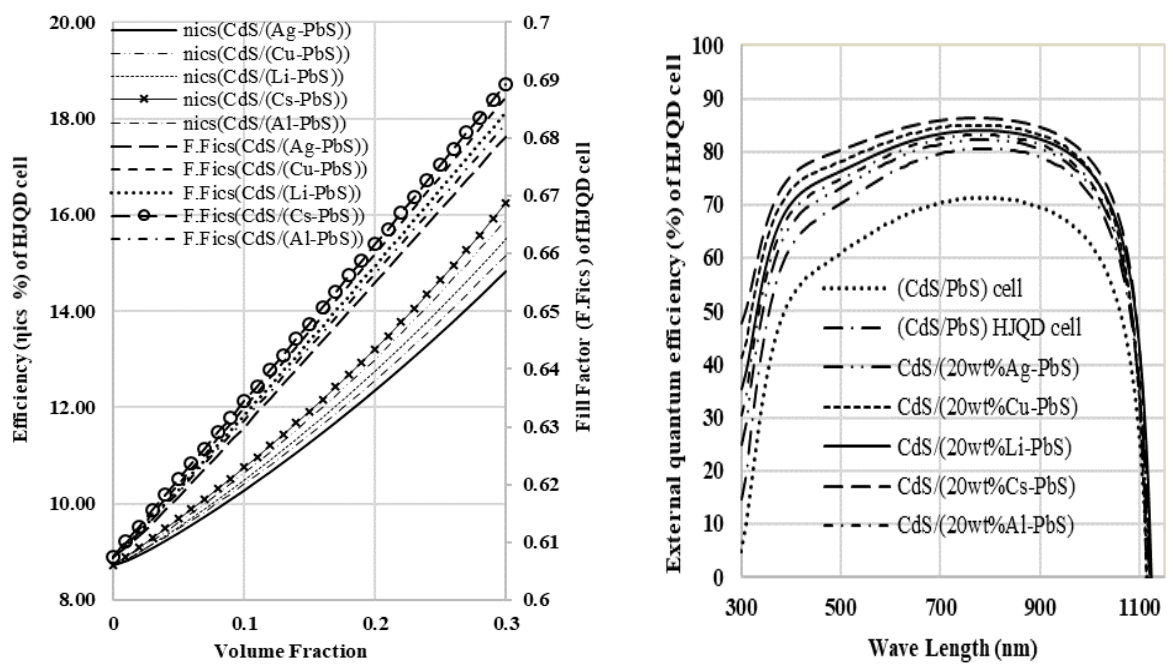

Figure 4. Fill factor, energy conversion efficiency and external quantum efficiency of heterojunction quantum dot ITO/QDCdS/metallics-PbS/Au thin film solar cell

\section{CONCLUSION}

Quantum dot aluminum, lithium, cesium, copper or silver core concern to reduce the dielectric constant and refractive index of PbS shells. On the other side, the energy band gap of PbS shell enhanced with increasing the volumetric concentration of selected metallics core. The absorption coefficient and electron hole generation rate of metallics-PbS core/shell absorber layer has been increased by increasing the volume fraction of the proposed metallics cores. The enhancement in the energy band gap and the electronhole generation rate results increasing in the open circuit voltage, short circuit current, the maximum power point and so efficiency of HJQD CdS/PbS thin film. Cesium has been the best quantum dot core for enhancing the performance of $\mathrm{HJQD} \mathrm{CdS} / \mathrm{PbS}$ cell, then; QD $\mathrm{Cu}$ core has been the second order for improving the performance of HJQD CdS/PbS cell. However, QD Silver core has been the least one for improving the performance of HJQD CdS/PbS cell

\section{REFERENCES}

[1] M. Rasukkannu, D. Velauthapillai, and V. Ponniah, "A promising high-efficiency photovoltaic alternative non-silicon material: a first-principle investigation,” Scripta Materialia, vol. 156, pp. 134-137, Nov. 2018, doi: 10.1016/j.scriptamat.2018.07.027.

[2] T. Blachowicz and A. Ehrmann, "Recent developments of solar cells from PbS colloidal quantum dots," Applied Sciences, vol. 10, no. 5, Mar. 2020, Art no. 1743, doi: 10.3390/app10051743.

[3] M. Rasukkannu, D. Velauthapillai, F. Bianchini, and P. Vajeeston, "Properties of novel non-silicon materials for photovoltaic applications: a first-principle insight," Materials, vol. 11, no. 10, Oct. 2018, Art. no. 2006, doi: 10.3390/ma11102006.

[4] S. R. Rosario et al., "Deposition of p-type Al doped PbS thin films for heterostructure solar cell device using feasible nebulizer spray pyrolysis technique," Physica B: Condensed Matter, vol. 575, Dec. 2019, Art. no. 411704, doi: 10.1016/j.physb.2019.411704.

[5] Y. Da and Y. Xuan, "Effect of temperature on performance of nanostructured silicon thin-film solar cells," Solar Energy, vol. 115, pp. 109-119, May 2015, doi: 10.1016/j.solener.2015.02.025.

[6] Y. Da and Y. Xuan, "Role of surface recombination in affecting the efficiency of nanostructured thin-film solar cells," Optics Express, vol. 21, no. 6, Nov. 2013, Art. no. 1065, doi: 10.1364/oe.21.0a1065.

[7] A. Braun, E. A. Katz, and J. M. Gordon, "Basic aspects of the temperature coefficients of concentrator solar cell performance parameters," Progress in Photovoltaics: Research and Applications, vol. 21, no. 5, pp. 1087-1094, May 2013, doi: 10.1002/pip. 2210

[8] S. K. Sharma and K. Ali, Solar cells. Cham: Springer International Publishing, 2020.

[9] A. Bozzola, M. Liscidini, and L. C. Andreani, "Photonic light-trapping versus Lambertian limits in thin film silicon solar cells with 1D and 2D periodic patterns," Optics Express, vol. 20, no. 2, pp. 224-244, Jan. 2012, doi: 10.1364/oe.20.00a224.

[10] J. Tang et al., "Quantum junction solar cells," Nano Letters, vol. 12, no. 9, pp. 4889-4894, Aug. 2012, doi: 10.1021/nl302436r.

[11] J. H. Bang and P. V Kamat, "Quantum dot sensitized solar cells. A tale of two semiconductor nanocrystals: CdSe and CdTe," ACS Nano, vol. 3, no. 6, pp. 1467-1476, May 2009, doi: 10.1021/nn900324q.

[12] M. C. Beard et al., "Multiple exciton generation in colloidal silicon nanocrystals," Nano Letters, vol. 7, no. 8, pp. 2506-2512, Jul. 2007, doi: 10.1021/n10714861.

[13] R. Debnath et al., "Depleted-heterojunction colloidal quantum dot photovoltaics employing low-cost electrical contacts," Applied Physics Letters, vol. 97, no. 2, Jul. 2010, Art. no. 023109, doi: 10.1063/1.3463037.

[14] X. Huang et al., "A flexible photoelectrode for CdS/CdSe quantum dot-sensitized solar cells (QDSSCs)," Chemical Communications, vol. 47, no. 9, pp. 2664-2666, 2011, doi: 10.1039/c0cc04419a.

[15] P. V. Kamat, "Boosting the efficiency of quantum dot sensitized solar cells through modulation of interfacial charge transfer," Accounts of Chemical Research, vol. 45, no. 11, pp. 1906-1915, Apr. 2012, doi: 10.1021/ar200315d 
[16] C. P. Liu et al., "Hybrid photovoltaic cells based on $\mathrm{ZnO} / \mathrm{Sb} 2 \mathrm{~S} 3 / \mathrm{P} 3 \mathrm{HT}$ heterojunctions," Physica Status Solidi (B) Basic Research, vol. 249, no. 3, pp. 627-633, Oct. 2012, doi: 10.1002/pssb.201147393.

[17] K. Y. Niu, M. Liu, K. A. Persson, Y. Han, and H. Zheng, "Strain-mediated interfacial dynamics during Au-PbS core-shell nanostructure formation," ACS Nano, vol. 10, no. 6, pp. 6235-6240, May 2016, doi: 10.1021/acsnano.6b02331.

[18] W. Qin, J. Hou, and D. A. Bonnell, "Effect of interface atomic structure on the electronic properties of nano-sized metal-oxide interfaces," Nano Letters, vol. 15, no. 1, pp. 211-217, Dec. 2015, doi: 10.1021/n1503389b.

[19] H. Y. Lin, Y. F. Chen, J. G. Wu, D. I. Wang, and C. C. Chen, "Carrier transfer induced photoluminescence change in metalsemiconductor core-shell nanostructures," Applied Physics Letters, vol. 88, no. 16, Apr. 2006, Art. no. 161911, doi: 10.1063/1.2197311.

[20] W. Lu, B. Wang, J. Zeng, X. Wang, S. Zhang, and J. G. Hou, "Synthesis of core/shell nanoparticles of Au/CdSe via Au-Cd bialloy precursor," Langmuir, vol. 21, no. 8, pp. 3684-3687, Feb. 2005, doi: 10.1021/la0469250.

[21] K. P. Bhandari et al., "Thin film solar cells based on the heterojunction of colloidal PbS quantum dots with CdS," Solar Energy Materials and Solar Cells, vol. 117, pp. 476-482, Oct. 2013, doi: 10.1016/j.solmat.2013.07.018.

[22] B. Peng et al., "Fluorophore-doped core-multishell spherical plasmonic nanocavities: resonant energy transfer toward a loss compensation," ACS Nano, vol. 6, no. 7, pp. 6250-6259, Jun. 2012, doi: 10.1021/nn301716q.

[23] Y. Wang, T. Yang, M. T. Tuominen, and M. Achermann, "Radiative rate enhancements in ensembles of hybrid metalsemiconductor nanostructures," Physical Review Letters, vol. 102, no. 16, Apr. 2009, doi: 10.1103/PhysRevLett.102.163001.

[24] N. Zhang, S. Liu, and Y. J. Xu, "Recent progress on metal core@semiconductor shell nanocomposites as a promising type of photocatalyst," Nanoscale, vol. 4, no. 7, pp. 2227-2238, 2012, doi: 10.1039/c2nr00009a

[25] P. Holmström, L. Thyĺn, and A. Bratkovsky, "Dielectric function of quantum dots in the strong confinement regime," Journal of Applied Physics, vol. 107, no. 6, Mar. 2010, Art. no. 64307, doi: 10.1063/1.3309343.

[26] C. Hamaguchi, Basic semiconductor physics. Berlin, Heidelberg: Springer Berlin Heidelberg, 2010.

[27] J. Jimenez and J. W. Tomm, Spectroscopic analysis of optoelectronic semiconductors, vol. 202. Springer International Publishing, 2016.

[28] P. Harrison, Quantum wells, wires and dots: theoretical and computational physics of semiconductor nanostructures, 3rd ed. Wiley, 2011.

[29] B. K. Ridley, Quantum processes in semiconductors. Oxford University Press, 2013.

[30] M. M. El-Nahass, G. M. Youssef, and S. Z. Noby, "Structural and optical characterization of CdTe quantum dots thin films," Journal of Alloys and Compounds, vol. 604, pp. 253-259, Aug. 2014, doi: 10.1016/j.jallcom.2014.03.104.

[31] A. Thabet, S. Abdelhady, and Y. Mobarak, "Design modern structure for heterojunction quantum dot solar cells," International Journal of Electrical and Computer Engineering (IJECE), vol. 10, no. 3, pp. 2918-2925, Jun. 2020, doi: 10.11591/ijece.v10i3.pp2918-2925.

[32] K. E. Jasim, "Quantum dots solar cells," in Solar Cells - New Approaches and Reviews, 2015, pp. 303-331.

[33] P. Singh and N. M. Ravindra, "Temperature dependence of solar cell performance - An analysis," Solar Energy Materials and Solar Cells, vol. 101, pp. 36-45, Jun. 2012, doi: 10.1016/j.solmat.2012.02.019.

[34] M. A. Mannan, M. S. Anjan, and M. Z. Kabir, "Modeling of current-voltage characteristics of thin film solar cells," Solid-State Electronics, vol. 63, no. 1, pp. 49-54, Sep. 2011, doi: 10.1016/j.sse.2011.05.010.

[35] A. T. Mohamed, S. A. Ahmed, K. Ebnalwaled, and A. Ibrahim, "Improvement optical and electrical characteristics of thin film solar cells using nanotechnology techniques," International Journal of Electronics and Telecommunications, vol. 65, pp. 625-634, 2019, doi: 10.24425/ijet.2019.129822.

[36] S. K. Tripathy, "Refractive indices of semiconductors from energy gaps," Optical Materials, vol. 46, pp. 240-246, Aug. 2015, doi: 10.1016/j.optmat.2015.04.026. 